\title{
Mental health burden and unmet needs for treatment: a call for justice
}

Tea Dakić

\section{Summary}

The massive burden of mental disorders adversely affects global health, economy and human rights situations. Yet research investments are shifting from psychiatry toward other more cost-effective fields of medicine. This editorial calls for conscious capitalism and prioritisation of mental health by reflecting on mental health disparities through the prism of justice.

\section{Declaration of interest}

None.

\section{Keywords}

Mental disease burden; justice; treatment gap; research gap; conscious capitalism.

\section{Copyright and usage}

(c) The Authors 2019.
Tea Dakić (pictured) is a medical doctor and psychiatrist at the Clinical Centre of Montenegro and holds a Master of Science in Bioethics. They are also experienced in human rights analysis, monitoring and education.

One of the common criticisms of mental healthcare is that, despite years of research, there have been few significant advances. Although advances in basic sciences greatly influence contemporary medical treatment, individuals with psychiatric disorders are still largely excluded from these progressions in healthcare owing to both social and scientific discrimination. The exclusion of these individuals from the benefits enjoyed by other members of society creates an under-recognised and worrisome cause of health inequity.

In this editorial I argue that the lack of advances in psychiatric treatment can be attributed to a reduction in research into mental health, especially into treatments, both pharmacological and psychological. This lack of research leads to inequities in care provision and increases suffering. Under the conditions of scarcity of resources and competition to obtain profits, the failure of global society to eliminate barriers that prevent fair equality of opportunity demonstrates that one of the foundational principles of bioethics respect for justice - is being ignored. ${ }^{1}$ The current situation in allocation of resources in healthcare and research is unacceptable and must be amended to ensure justice and avoid undeserved restrictions on the basic human rights of people with mental disorders.

\section{Closing the door on research}

Mental disorders historically were not a global health priority. Despite their major contribution to the global burden of disease, there is currently no adequate response to this burden. ${ }^{2}$ With the exception of ketamine and current enthusiasm about its rapid antidepressant effects, it has been decades since the last 'blockbuster' psychiatric drugs. The world's biggest funder of mental health research, the USA's National Institute of Mental Health (NIMH), has been gradually cutting down on the clinical trials funding. In just 6 years, between 2009 and 2015, the number of clinical trials funded by the NIMH dropped by $45 \% .{ }^{3}$ Major pharmaceutical companies have also been withdrawing from psychiatric medication research and drug discovery. The reasons behind this major disengagement in psychopharmacology apparently lay behind the belief that the probability of success is relatively low, and expenditures are disproportionately high. Most companies that pulled away from psychiatry turned to the field of oncology, immunology and diabetes research, where risks are lower and profits are higher. ${ }^{4}$ Putting it more explicitly, although other groups of patients have a prospect of benefitting from this major shift in research focus, those suffering from mental disorders are left behind, with a large burden of disease and in an already deep treatment and research gap.

\section{Treatment and research gap}

The treatment gap for persons suffering from mental disorders exceeds $50 \%$ globally. It is estimated that in low- and middleincome countries, up to $85 \%$ of individuals with mental disorders receive no treatment. ${ }^{2}$ Even when treatments are available and accessible, they often fail to be effective or evidence-based. Although the lack of research into pharmacological treatments of mental disorders may partially explain the magnitude of this gap, it must, however, be noted that research into psychotherapeutic treatments demonstrated some promising developments. Functional neuroimaging studies of the brain have provided an abundance of tangible evidence demonstrating the effectiveness of psychotherapy. Yet, the number of patients who are either not being offered psychotherapeutic treatment or are not able to access it is increasing.

These large treatment gaps seem to uphold stigma, discrimination and social exclusion experienced by the persons with mental disorders on daily basis. Globally low responsiveness for the needs of persons affected by mental disorders causes their unjust exclusion and further breaches their basic human rights, such as the right to evidence-based treatment and the highest attainable standard of health.

Every person is entitled to the highest attainable standard of health as one of their fundamental human rights. For those suffering from mental disorders, the withdrawal of the biggest funders from mental health research is a barrier on the way to realisation of this right. Over and above the lack of access to mental health support, cutting down funds for psychiatric research represents a 'glass ceiling' that keeps those burdened by mental disorders from rising beyond a certain level of well-being. It prevents them from reaching higher levels of attainable standard of health that others suffering from more 'cost-effective' conditions enjoy. 
A rights-based approach to health creates a legal obligation to ensure appropriate, timely, acceptable and affordable healthcare to all. It also requires that the needs of those who are further behind and least well off must be prioritised to achieve greater equity.

\section{A call for justice and equity}

In the research ethics context, the most commonly used principle of justice is that of distributive justice, which requires the equitable distribution of the burdens and the benefits. Any act that denies people benefits to which they have a right, or distributes burdens unfairly, is thus considered failure to treat them justly. ${ }^{1}$ Until recently, ethical analyses looking at the issue of research on vulnerable populations like people with mental health conditions have focused mainly on minimising risks, harms and burdens to the research participants. Nowadays, it seems that risk analysis is predominantly oriented toward safeguarding the research sponsors and minimising their financial burdens by withdrawing from research on conditions they are least likely to profit from. However, principles of ethics still recognise that depriving individuals and groups of the direct and indirect benefits arising from research is in itself unjust. The disengagement from psychiatric research is inherently harmful and discriminatory toward people suffering from mental disorders. Consequentially, these individuals are denied benefits on the basis of their undeserved characteristics.

Justice also refers to the ethical obligation to give to each person according to their need. ${ }^{1}$ Groups of potential research participants should be considered for inclusion if they have a greater need to receive the anticipated benefits. Because people with mental disorders account for a large number of persons with disabilities, there is a great need to prevent and treat these individually and socially disabling and burdensome conditions. Research is necessary to better understand the underlying conditions of those disabilities. Abandoning psychiatric research because of its high risks and low profits is not an ethically neutral practice, as it impedes the efforts to develop new treatments and preventive measures that could meet the needs of persons suffering from mental disorders.

The principle of justice can also be viewed as a requirement for equality of opportunity and fair access to research, both in terms of participation in research and access to the results of research. ${ }^{1}$ This egalitarian view of justice emphasises the ethical obligation to eliminate or reduce social barriers that prevent equality of opportunity. Specifically, justice requires that individuals or groups not be excluded from participation in research for reasons that are unrelated to the scientific question itself. The inclusion and exclusion criteria for participation in research should be scientifically and ethically justified, rather than arbitrarily or conveniently chosen, particularly when there is no ground for morally acceptable discrimination in allocations of benefits of research that other members of society enjoy. The exclusion of individuals suffering from mental disorders from research denies them from the benefits of fair participation in society and results in limited information about the diagnosis, prevention and treatment of conditions and disorders that afflict them.

\section{Global burden of mental disorders and the need for research}

Mental health disorders are among top ten leading causes of disability globally. It is estimated that around 300 million persons are affected by depression, 60 million by bipolar affective disorder, 23 million by schizophrenia and another 50 million people by dementia. $^{2}$ This burden does not just gravely affect the overall health of the human population, but also largely afflicts human rights situation and economy all around the globe. ${ }^{2}$ Loss of productivity, sickness absence, unemployment, physical comorbidity, increased hospitalisation or premature death both of persons affected and their carers are just some of the direct and indirect costs of mental disorders burden. The massive burden of poor mental health impels the need to improve the quality of mental healthcare by making it a priority in creating healthcare policies worldwide.

\section{Conclusions and recommendations}

An ideal approach to advancing science and meeting the needs of those suffering from mental health disorders would be patientcentred, needs-centred and equity-centred. Unfortunately, what we are currently witnessing is the scarcity of mental health research; this state of affairs is profits-driven and essentially unjust. Even if we were to accept that the world we live in is a capitalistic one, a shift toward a concept of 'conscious capitalism' may be a win-win situation for all of the parties involved. ${ }^{5}$

The model of conscious capitalism encompasses prosperity, compassion and solidarity. It offers progress and profits, while serving a purpose to ensure the highest attainable level of healthcare and restore realisation of the human rights of those suffering from mental disorders. There is a potential to create value for all relevant stakeholders; a potential to preserve the importance of financial gain, while recognising the capability of big companies to have a positive impact on the world and the power of governments to regulate the market. If governments were to create more favourable conditions, incentives or subventions for research sponsors and investigators, then the big pharmaceutical companies may be more inclined to participate in psychiatric research. More research implies greater knowledge and better chances for new and efficient drugs. Better treatment options consequently improve the overall health and well-being of those in need, decrease health burden and reduce the number of years lost to disability. In return, this means additional labour force for the government and less expenditure for social security and disability benefits, which in turn creates an effective economy.

Tea Dakić (D, MD, MSc, Psychiatrist, Clinic for Psychiatry, Clinical Centre of Montenegro, Montenegro. Email: teapg@t-com.me

First received 1 Nov 2018, final revision 7 Nov 2019, accepted 8 Nov 2019

\section{References}

1 Beauchamp TL, Childress JF. Chapter 6: Justice. In Principles of Biomedical Ethics, 5th edn (eds TL Beauchamp, JF Childress): 225-35. Oxford University Press, 2001

2 World Health Organization (WHO). Fact Sheet on Mental Disorders. WHO, 2018. (http://www.who.int/mediacentre/factsheets/fs396/en/).

3 Reardon S. US mental-health agency's push for basic research has slashed support for clinical trials. Nat News 2017; 546(7658): 339.

4 Miller G. Is pharma running out of brainy ideas? Science 2010; 329(5991): 502-4.

5 Mackey J, Sisodia R. 'Conscious Capitalism' Is Not an Oxymoron. Harvard Business Review, 2013 (https://hbr.org/2013/01/cultivating-a-higher-conscious). 